\title{
Le virus du Nil occidental au Canada : un virus en évolution permanente, mais présent pour de bon
}

\author{
Zheng $\mathrm{H}^{1}$, Drebot $\mathrm{MA}^{2}$, Coulthart MB ${ }^{1 *}$ \\ 1 Centre des maladies infectieuses d'origine alimentaire, environnementale et zoonotique, Agence de la santé publique du Canada, \\ Ottawa, Ontario \\ 2 Laboratoire national de microbiologie, Agence de la santé publique du Canada, Winnipeg (Manitoba) \\ *Auteur-ressource : michael.coulthart@phac-aspc.gc.ca
}

\section{Résumé}

L'incidence du virus du Nil occidental a varié au Canada au cours des douze dernières années, mais il est peu probable que ce virus disparaisse. Les modèles de changements climatiques, qui reflètent un réchauffement des températures et un changement de configuration des précipitations, présagent une expansion géographique du virus du Nil occidental dans certaines régions du Canada, telles que les provinces des Prairies. Ces changements prévus dans la répartition du virus du Nil occidental pourraient également être accompagnés de modifications génétiques du virus ou de l'éventail d'espèces d'oiseaux et d'insectes hôtes infectés. Pour éviter ce risque, l'accent doit être mis sur la prévention de l'exposition aux moustiques infectés, l'exécution d'une surveillance stricte du virus du Nil occidental, le contrôle des moustiques vecteurs et la promotion de la sensibilisation du public et des professionnels.

\section{Introduction}

Le virus du Nil occidental (VNO), une espèce du genre Flavivirus répandue dans le monde entier, infecte un large éventail de mammifères, d'oiseaux, de reptiles et d'amphibiens, ainsi que diverses espèces de moustiques, y compris des espèces du genre Culex. Le virus se perpétue principalement dans les populations d'oiseaux, où il est transmis par les moustiques; la transmission zoonotique survient lorsqu'un moustique qui s'est nourri du sang d'un oiseau infecté pique ensuite un humain. L'infection par le virus du Nil occidental peut également être transmise d'une personne à une autre par des interventions médicales, en particulier les transfusions sanguines et les greffes d'organes $(1,2)$. Depuis 1999, année où il a été reconnu pour la première fois chez l'être humain en Amérique du Nord, le virus du Nil occidental s'est propagé sur tout le continent, au Canada et aux États-Unis, avec des éclosions annuelles dont l'intensité et la répartition régionale sont variables.

Le but de ce commentaire est de présenter un point de vue laissant entendre que, bien que l'incidence du virus du Nil occidental ait varié au cours des dix dernières années ou plus, le virus continuera d'avoir des conséquences importantes en matière de santé individuelle et de santé publique dans un avenir prévisible, et une action concertée est nécessaire afin de minimiser ces conséquences. Nous examinerons l'épidémiologie du virus du Nil occidental, fournirons un aperçu de l'épidémie du virus du Nil occidental en Amérique du Nord, et terminerons en mettant l'accent sur le besoin de vigilance soutenue quant à ce défi de santé publique.

\section{Épidémiologie}

Bien qu'on ne connaisse pas la proportion d'infection parmi les personnes piquées par un moustique porteur du virus du Nil occidental, les enquêtes sérologiques et les études menées chez les donneurs virémiques indiquent que 70 à 80 $\%$ des infections sont asymptomatiques ou non reconnues(3,4). La gravité de la maladie symptomatique, qui apparaît généralement de 2 à 15 jours après l'infection, va de la maladie fébrile transitoire avec maux de tête, frissons, éruption cutanée, nausées et douleurs musculaires (dans la majorité des cas), à la maladie neurologique grave et parfois mortelle sous forme de méningite, d'encéphalite ou de poliomyélite/paralysie flasque aiguë (chez environ $1 \%$ des personnes infectées)(5). La plupart des personnes touchées se rétablissent complètement de la maladie aiguë, vraisemblablement avec une immunité à vie, mais le rétablissement peut être long et accompagné de séquelles pouvant être permanentes, comme de la faiblesse, de la fatigue, des déficiences neurologiques et cognitives ainsi que des problèmes psychiatriques. Les personnes ayant des problèmes médicaux sous-jacents et les personnes âgées de 
plus de 70 ans semblent être particulièrement sensibles à ces effets(2,6). Il n'existe actuellement aucun vaccin approuvé contre le virus du Nil occidental, ni aucun traitement précis pour les humains.

\section{Le virus du Nil occidental en Amérique du Nord}

Le tout premier cas de virus du Nil occidental a été déclaré en Ouganda, en 1937. Depuis, des épidémies locales ou régionales de cas relativement bénins de virus du Nil occidental ont été signalées de façon intermittente en Afrique et en Israël, jusque dans les 1990, lorsque des éclosions de cas graves de la maladie ont eu lieu dans l'ouest de la Russie ainsi que dans le sud et l'est de l'Europe(2). Des épidémies dispersées continuent de se produire en Europe, peut-être à cause d'introductions répétées par des oiseaux migrateurs(7). Les premiers cas autochtones de virus du Nil occidental en Amérique du Nord ont été enregistrés à New York, en août 1999(8). La propagation du virus du Nil occidental a été spectaculaire : il a atteint l'est du Canada, le sud-est des États-Unis, le Mexique et les Caraïbes en 2001, la côte Ouest des États-Unis en 2003, l'Amérique du Sud en 2005 et la côte Ouest du Canada en 2008(9). On considère désormais que le virus est bien implanté dans les Amériques.

Le virus du Nil occidental a été détecté au Canada pour la première fois en 2001, chez des oiseaux et des moustiques provenant de l'Ontario(10). La documentation des cas a commencé l'année suivante et depuis, le virus du Nil occidental chez l'humain a été signalé dans dix provinces et territoires canadiens (y compris des cas liés à des voyages au Nouveau-Brunswick, en Nouvelle-Écosse, à l'île-du-Prince-Édouard et au Yukon). Au total, 5454 cas de virus du Nil occidental et d'infection asymptomatique ont été signalés à l'Agence de la santé publique du Canada entre 2002 et 2013, y compris 1072 cas de maladies neurologiques liées au virus du Nil occidental. Les chiffres susmentionnés permettent d'estimer que 18000 à 27000 infections humaines par le virus du Nil occidental se sont produites au Canada depuis 2002, et que le taux proportionnel de maladies neurologiques pourrait être supérieur à celui signalé aux États-Unis. Plusieurs enquêtes sérologiques ont été menées au Canada pour estimer les taux d'exposition au virus du Nil occidental chez l'humain, et les résultats se situent généralement entre 3 et $5 \%$. Cependant, dans les régions rurales de la Saskatchewan, après la saison du virus du Nil occidental de 2003, la séroprévalence était de près de $17 \%(11)$.

Il convient de noter que l'incidence annuelle déclarée du virus du Nil occidental à l'échelle nationale a varié de façon spectaculaire, allant d'un total de cinq cas en 2010 à des pics à 1495 et à 2401 cas en 2003 et en 2007, respectivement. (Figure 1)

La variation régionale s'est également avérée importante : par exemple, la majorité des cas au Canada ont été signalés dans les provinces des Prairies (Alberta, Saskatchewan et Manitoba) en 2003 et en 2007, et dans les provinces du Centre (Ontario et Québec) en 2002 et en 2012(12). On peut donc présumer que les coûts économiques à long terme des soins actifs et des effets persistants sur la santé des personnes touchées par le virus du Nil occidental sont importants, malgré l'absence de données appuyant des estimations réalistes de ces coûts pour le Canada. L'estimation récente du coût total pour l'économie des États-Unis de 1999 à 2012 se situait entre 700 millions et 1 milliard de dollars(13). 
Figure 1. Nombre annuel de cas de virus du Nil occidental chez l'humain et d'infections asymptomatiques signalés à l'Agence de la santé publique du Canada (2002-2013)

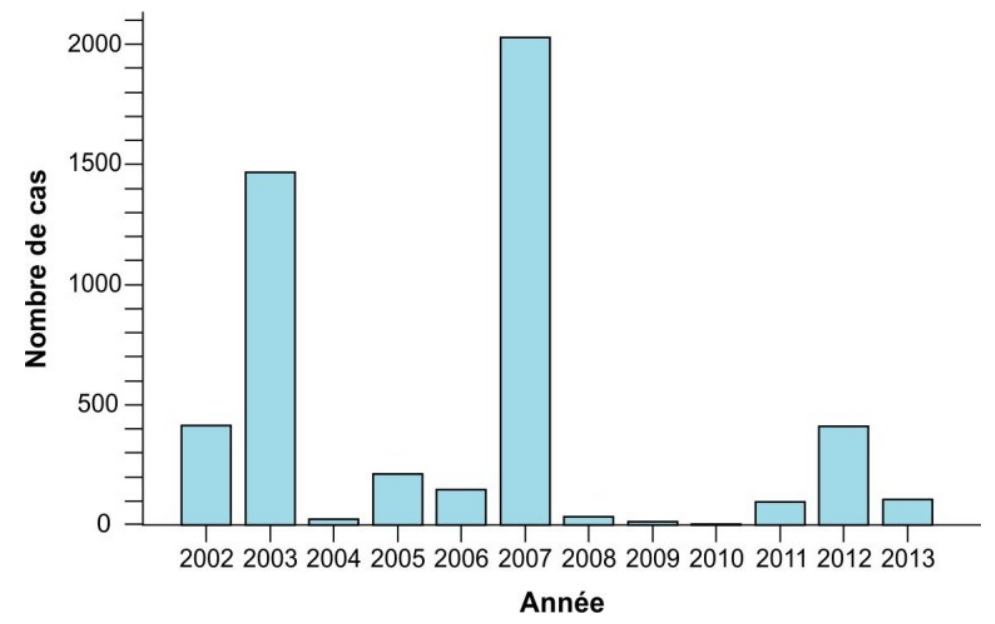

\section{Évolution du virus du Nil occidental}

Tout au long de son évolution, le virus du Nil occidental a subi une diversification génétique considérable, donnant lieu à la présence de quatre lignées principales, dont deux (lignées 1 et 2) provoquent la maladie chez l'humain. La lignée 2, qui n'a pas encore été identifiée en Amérique du Nord, a récemment été à l'origine de cas de virus du Nil occidental chez l'humain en Europe(7). Au sein de la lignée 1, qui est la plus répandue à l'échelle mondiale, un certain nombre de souches ont été déterminées et certaines modifications génétiques ont été associées à la colonisation en Amérique du Nord et au comportement biologique du virus, en particulier chez les oiseaux et les moustiques(14). Par exemple, la souche NY99 du virus du Nil occidental qui a initialement colonisé l'est des États-Unis comporte la même modification génétique qu'une souche aviaire israélienne de 1998, et cette modification semble donner au virus la capacité de se répliquer à des niveaux plus élevés chez les oiseaux(15). La souche NY99 a elle-même été rapidement remplacée par une souche dérivée (WN02) qui semble capable d'envahir plus rapidement les glandes salivaires des moustiques du genre Culex après la piqûre, en particulier à des températures plus élevées, ce qui laisse supposer une capacité à se propager plus rapidement lorsqu'il fait plus chaud(16).

Ainsi, en augmentant le potentiel de reproduction et la virulence du virus du Nil occidental chez les moustiques et les oiseaux, respectivement, la modification génétique semble avoir facilité l'établissement et la propagation du virus du Nil occidental en Amérique du Nord, ainsi que sa capacité à provoquer des éclosions de la maladie. On s'attend à ce que ces effets soient à leur tour amplifiés par les changements environnementaux provoqués par l'être humain. Ainsi, une étude menée récemment en Californie a découvert des liens entre le revenu par habitant et des facteurs connexes (p. ex. la densité de piscines mal entretenues) et la prévalence de l'infection par le virus du Nil occidental chez les moustiques et les humains(17). Un autre groupe de recherche a découvert une corrélation négative entre la diversité des espèces d'oiseaux, souvent compromise par l'activité humaine, et les taux locaux d'infection par le virus du Nil occidental chez les moustiques du genre Culex dans une banlieue de Chicago(18).

À plus grande échelle, en plus du réchauffement des températures et de l'évolution des schémas de précipitation, les modèles de changements climatiques indiquent une expansion géographique du virus du Nil occidental en Amérique du Nord vers des régions où les nombres d'hôtes humains et animaux non exposés précédemment sont plus élevés(19). Certaines régions du Canada, comme les provinces des Prairies, pourraient être particulièrement soumises à ces effets(20). Ces changements dans la répartition du virus du Nil occidental pourraient également être accompagnés d'autres modifications génétiques du virus ou de l'éventail d'espèces d'oiseaux et d'insectes hôtes 
infectés. Combinées à la corrélation positive connue entre la prévalence du virus du Nil occidental et la température, et la corrélation négative (plus ou moins prévue) entre le virus et les quantités de précipitations, ces considérations semblent indiquer que le risque de santé publique lié au virus du Nil occidental pourrait augmenter en Amérique du Nord au cours des prochaines décennies(16,19).

\section{Nécessité de la prévention}

Tel qu'il est mentionné ci-dessus, il existe des interactions complexes entre le virus du Nil occidental, ses nombreux hôtes (insectes, oiseaux et mammifères) et l'environnement. C'est pourquoi il n'a pas encore été possible de prévoir la survenue du virus du Nil occidental à un niveau spatial suffisamment détaillé pour permettre une intervention de santé publique locale très ciblée. Par conséquent, il est clair que pour réduire au minimum les répercussions du virus du Nil occidental sur la santé des Canadiens, l'accent doit être mis sur la prévention primaire de l'exposition humaine aux moustiques pouvant être porteurs du virus, en s'appuyant sur une surveillance stricte du virus du Nil occidental, un contrôle des moustiques vecteurs et une sensibilisation du public et des professionnels. Au Canada, un certain nombre de ces approches préventives sont en place. Par exemple, le virus du Nil occidental est une maladie à déclaration obligatoire à l'échelle nationale, provinciale et territoriale au Canada, et une surveillance nationale intégrée a lieu grâce à un partenariat fédéral-provincial-territorial (FPT) depuis 2002(10,12). L'effort de surveillance nationale est fondé sur la transmission hebdomadaire de données de surveillance concernant les humains, les chevaux, les oiseaux et les moustiques à l'Agence de la santé publique du Canada. Ces données sont fournies par divers partenaires, y compris les ministères provinciaux et territoriaux de la santé, la Société canadienne du sang et HémaQuébec, l'Agence canadienne d'inspection des aliments ainsi que le Centre canadien coopératif de la santé de la faune. Cette information est ensuite regroupée dans des rapports hebdomadaires nationaux(12) pendant la saison où le risque est maximal, tel qu'il est déterminé par un groupe de travail fédéral-provincial-territorial au début de chaque été. Les rapports hebdomadaires sont complétés par des renseignements sur l'activité du virus du Nil occidental aux États-Unis et en Europe.

Les municipalités entreprennent souvent un contrôle ciblé des populations de moustiques, en fonction de l'information sur l'activité des moustiques, les taux d'infection et la survenue de cas de virus du Nil occidental chez l'humain ou animal dans la région. Les autres mesures importantes de santé publique à l'échelle nationale comprennent le dépistage systématique des dons de sang par la Société canadienne du sang et Héma-Québec pour prévenir la transmission du virus du Nil occidental par le sang et, souvent, pour fournir un indicateur précoce d'activité du virus du Nil occidental au cours d'une saison donnée et offrir un soutien expert scientifique, épidémiologique et de laboratoire (à l'échelle fédérale, par l'entremise du Laboratoire national de microbiologie et le Centre des maladies infectieuses d'origine alimentaire, environnementale et zoonotique). Évidemment, il y a également beaucoup de mesures que peuvent prendre les Canadiens pour se protéger et protéger leurs familles de l'exposition aux moustiques pouvant être porteurs du virus du Nil occidental. Ces mesures comprennent la réduction de l'eau stagnante afin de diminuer l'abondance locale de moustiques, l'utilisation d'insectifuges contenant l'ingrédient actif $N, N$-diéthyl- $m$-toluamide (DEET), la réduction des activités de plein air aux moments où les moustiques sont les plus actifs ainsi que le port de vêtements protecteurs(21).

\section{Conclusions}

Le virus du Nil occidental et les problèmes de santé qui en découlent demeureront vraisemblablement des préoccupations importantes pour le Canada dans un avenir proche. La surveillance, le diagnostic médical et le dépistage, le contrôle des moustiques et les programmes de sensibilisation du public sont autant de mesures qui ont été instaurées au Canada. Toutefois, la nature dynamique de l'agent pathogène, la complexité de ses interactions écologiques et l'imprévisibilité de son comportement détaillé dans le temps et dans l'espace indiquent que des efforts supplémentaires sont nécessaires pour maintenir et améliorer l'efficacité de la prévention primaire. La surveillance, la recherche, le soutien logistique et les mesures d'intervention prises par les gouvernements fédéraux, provinciaux et territoriaux continueront à jouer des rôles clés dans ces efforts. Toutefois, la question du virus du Nil occidental est importante pour tous les Canadiens, et l'accès à des connaissances à jour et scientifiquement étayées continuera d'avoir un impact positif majeur. 


\section{Références}

1. Fearon MA. West Nile story: the transfusion medicine chapter. Future Virology 2011;6(12):1423-1434.

2. Petersen LR, Brault AC, Nasci RS. West Nile virus: review of the literature. JAMA 2013 Jul 17;310(3):308-315.

3. Mostashari F, Bunning ML, Kitsutani PT, Singer DA, Nash D, Cooper MJ, et al. Epidemic West Nile encephalitis, New York, 1999: results of a household-based seroepidemiological survey. Lancet 2001 Jul 28;358(9278):261-264.

4. Zou S, Foster GA, Dodd RY, Petersen LR, Stramer SL. West Nile fever characteristics among viremic persons identified through blood donor screening. J Infect Dis 2010 Nov 1;202(9):1354-1361.

5. Petersen LR, Carson PJ, Biggerstaff BJ, Custer B, Borchardt SM, Busch MP. Estimated cumulative incidence of West Nile virus infection in US adults, 1999-2010. Epidemiol Infect 2013 Mar;141(3):591-595.

6. Sejvar JJ. Clinical manifestations and outcomes of West Nile virus infection. Viruses 2014 Feb 6;6(2):606-623.

7. Sambri V, Capobianchi M, Charrel R, Fyodorova M, Gaibani P, Gould E, et al. West Nile virus in Europe: emergence, epidemiology, diagnosis, treatment, and prevention. Clin Microbiol Infect 2013 Aug;19(8):699-704.

8. Nash D, Mostashari F, Fine A, Miller J, O'Leary D, Murray K, et al. The outbreak of West Nile virus infection in the New York City area in 1999. N Engl J Med 2001 Jun 14;344(24):1807-1814.

9. Artsob H, Gubler DJ, Enria DA, Morales MA, Pupo M, Bunning ML, et al. West Nile virus in the New World: trends in the spread and proliferation of West Nile virus in the Western Hemisphere. Zoonoses Public Health 2009 Aug;56(6-7):357-369.

10. Drebot MA, Lindsay R, Barker IK, Buck PA, Fearon M, Hunter F, et al. West Nile virus surveillance and diagnostics: a Canadian perspective. Can J Infect Dis 2003 Mar;14(2):105-114.

11. Schellenberg TL, Anderson ME, Drebot MA, Vooght MT, Findlater AR, Curry PS, et al. Seroprevalence of West Nile virus in Saskatchewan's Five Hills Health Region, 2003. Can J Public Health 2006 Sep-Oct;97(5):369-373.

12. Public Health Agency of Canada (PHAC). West Nile virus MONITOR. 2014. http://www.phac-aspc.gc.ca/wnv-vwn/indexeng.php.

13. Staples JE, Shankar MB, Sejvar JJ, Meltzer MI, Fischer M. Initial and long-term costs of patients hospitalized with West Nile virus disease. Am J Trop Med Hyg 2014 Mar;90(3):402-409.

14. Reisen WK. Ecology of West Nile virus in North America. Viruses 2013 Sep 4;5(9):2079-2105.

15. Brault AC, Huang CY, Langevin SA, Kinney RM, Bowen RA, Ramey WN, et al. A single positively selected West Nile viral mutation confers increased virogenesis in American crows. Nat Genet 2007 Sep;39(9):1162-1166.

16. Kilpatrick AM, Meola MA, Moudy RM, Kramer LD. Temperature, viral genetics, and the transmission of West Nile virus by Culex pipiens mosquitoes. PLoS Pathog 2008 Jun 27;4(6):e1000092. 
17. Harrigan RJ, Thomassen HA, Buermann W, Cummings RF, Kahn ME, Smith TB. Economic conditions predict prevalence of West Nile virus. PLoS One 2010 Nov 12;5(11):e15437.

18. Hamer GL, Chaves LF, Anderson TK, Kitron UD, Brawn JD, Ruiz MO, et al. Fine-scale variation in vector host use and force of infection drive localized patterns of West Nile virus transmission. PLoS One 2011;6(8):e23767.

19. Harrigan RJ, Thomassen HA, Buermann W, Smith TB. A continental risk assessment of West Nile virus under climate change. Glob Chang Biol 2014 Feb 27.

20. Chen CC, Jenkins E, Epp T, Waldner C, Curry PS, Soos C. Climate change and West Nile virus in a highly endemic region of North America. Int J Environ Res Public Health 2013 Jul 22;10(7):3052-3071.

21. Public Health Agency of Canada (PHAC). West Nile virus - Protect Yourself! 2014. http://www.phac-aspc.gc.ca/wn-no/indexeng.php.. 